\title{
Prospect and Problems of Tourism Development in Nepal : A Case Study on Bhaktapur Darbar Square
}

Ananta Raj Dahal*

\begin{abstract}
Tourism sector is a very importance in Nepalese's economic activities. In this sector there are so many problems and opportunity. In this research had analysed the problems and prospects of tourism development in Nepal with reference to BhaktpurDurbar Square (BDS) in Bhaktpur district. Primary data were used for the main information and secondary data also used for supplementary sources of information. Primary data collected by direct personal interview through semi-structural questioner. Both local trade/business people and tourist those who were available in the time of survey were used as a samples.Tourist visit here for holiday pleasure, business and research purpose. Length of tourist stay is very few and time of re visit also few. For the development of tourism sector Nepal increase physical facilities and improve infrastructure of old and new tourism destination.
\end{abstract}

Keywords: Problem, Prospect, Tourism, Development and Tourist.

\section{Introduction}

The internal and external visitor who visit the different place of the own country or the different country are called the tourist. Tourism development is the burning issue of the present world aspects of economic activities for the country. From the developedof internal and external tourism to the country, it help to promote industrial development, employment opportunity, increase the economic activities etc.Satyal(1988) tourism denotes the movement of journey of human beings from one place to another, whether it may be within own country or second countries, or various purposes.WTO (1996)has defined "Tourism" imprecise tend as "Any person who travels to a country other than that is which he/she has his/her the usual residence, but outside his/her usual environment, for a period of at other than the exercise of an activity, remuneration from within the country visited. Term includes people traveling for, leisure, recreation and holidays, visiting friends, relatives, business and professional, health treatment, religion, pilgrimages and other purposes." Bulter (1980) mention the concept of tourism on cyclic model. He states the 7 statesof tourism are exploration, enlargement, inclusion, exacerbation, renewal, stagnation and downturn.Negi

*Mr. Dahal is a Lecturer at the Department of Economics,T.U., Patan Multiple Campus, Patan Dhoka. 
(1990) tourism is related to "Tour" which derived from the Latin word 'Tornos'. It means a tool for describing a circle or turners wheel. Poudyal (1994) Tourism is regarded as a very important industry to virtually all economic regardless of their level of economic development. It is an export industry and helps to correct any adverse trade balance in an economy. Das and Acharjee (2012)"tourism can be defined as the science, art and business of attracting and transporting visitors, accommodating them and graciously catering their needs and wants.

\subsection{Tourism in Nepal}

Nepal is one of the best destinations and an attractive zone for tourism for all over the world. The long term objective of the tourism development has to be considered and on integral part of overall economic development comparing to past years. The direct contribution of travel and tourism to the gross domestic product (GDP) was NPR 99.8bn, it is 4\% of total GDP in 2017 (WTTC 2018).Tourist inflow rate to Nepal has been increasing day by day. Viewing the importance of tourism industry, various governments as well as non-governmental organizations have carried our various policies the result was Tourist Information Centre was established in 1957 and 1959, respectively.

During the Eighth Five Year Development Plan (1992-97) period that the government of Nepal announced an Independent Tourism Policy 1995. It was announced with the aim of increasing national income, productivity, foreign currency, creating employment opportunities, improving regional imbalance and projecting the image of Nepal in the International arena through diversification of travel and tourism industries.

Similarly, Ministry of Culture Tourism and Civil Aviation (MOCTA) also conduct the major activities at different time period such as "Visit Nepal 1998" and "2011". After success of visit Nepal year 1998 and 2011 The Ministry of Culture Tourism and Civil Aviation (MoCTCA) has planned to organize "Visit Nepal Year, 2020" to promote that Nepal was a safe place to travel after the devastating Earthquake, 2015.

In course of tourism development in Country, Nepal had to face many challenges and problems on the way. Due to these problems, the tourism sector of Nepal is still in infant phase trying to grow bigger and better. Not only these problems were in the past but some of them still exist today. From the problem of economic crisis to the natural disaster, Nepal faced a lot of challenges but somehow it has overcome these and the tourism industry stands still.

Nepal has the richest and most diverse cultural landscapes. Nepal is the holy land of Lord Pashupatinath and Gautam Buddha, where the Hindu and Buddhists have lived together in great harmony for the centuries. Moreover, small portion of Muslims and Christians are also 
living in Nepal from the centuries without any religious riots that have made Nepal a best place for religious tourism for all particularly Hindus and Buddhas. The three ancient cities of the valley are Patan, Kathmandu and Bhaktapur represent an essence of harmony in urban design, stylish architecture and religious monuments unequalled in any other country. The ten monument zones of Nepal have been names as the world heritages sites by UNESCO and all of them are situated within the small confines of the valley. Burger (1978) tourism plays an important role in the Nepalese economy. Upadhyaya (2003)highlighted the importance of tourism in economic development for the promotion and development of tourism sector in Nepal. Satyal (1998) Nepal is traditionally a tourist destination. Nepal possesses a depository of places of widely historic interest. It is an ancient country with a rich heritage.Upadhayay (2011) entitled "Tourism as a leading sector in economic development of Nepal" Shrestha (2014) the contribution of tourism industry in economic development of Nepal, tourism industry plays a vital role in the country's economic development in a developing country like Nepal.Upadhayaya\&Agrawal (2006) tourism sector is given proper attention, it has the potential act to promote overall economic development of Nepal. The developed tourism sector implies multiplier effect in the growing economy. 'Along with business, services and technology, tourism considered a significant contributor to a city's prosperity and image' (The economic journal of Nepal vol.26, No.3, 2003 P.177). Basnet (2016) tourism has a positive impact on all social, economic and environmental aspect if managed and is not managed properly then the impact can be negative.Prasain (2016) the tourism has been understood as activities perform by travel makers to satisfy or address his/her purposes and needs by engaging in noneconomy staying, away from his/her usual residential environment for certain period of time.Dhakal(2015) has concluded that tourism prospects of Nepal seems very sound.

\subsection{Bhaktpur Durbar Square}

Bhaktapur is an ancient newer city located in the east corner of the Kathmandu Valley, 13 $\mathrm{km}$ (8miles) from the Kathmandu valley. Also known as an open museum, it is home to some of the best preserved historical monuments including palaces, courtyards, temples, pagodas, monuments, craftwork, hand-crafted peacock windows, etc. reflecting mostly Hinduism. It has two of the seven monument zones within the Kathmandu valley listed as a World Heritage Site by UNESCO. There is also a rich concentration of culture and tradition among the Newer of Bhaktapur. They have their own festivals, music and dances. The entire city is full of historical masterpieces. 


\section{Objective of the Study}

The main objectives of this study is to be evaluate the problems and prospects of the tourism developing in Nepal with special reference to BhaktpurDurbarsquare area of the Bhaktpur.

\section{Resesrch Methodology}

A number of steps were followed to accomplish this study.

\subsection{Research Design}

This paper aims to analyse the problems and prospects of tourism development, whichhad been dependent on primary data for the information basically, but some secondary data also used for the supplementary sources of information. Secondary data were collected from different related government and non-government organization and their publication. For primary information questioner survey held in BhaktpurDurbar Square area people related tourism industries/business and tourist who were being visiting there at the time of survey through semi-structure questioner.

\subsection{Sampling Design}

The study is problems and prospects of tourism development of Nepal with special references in the Bhaktpur Durbar Square of Bhaktpur district. The study had been examined the present situation of the tourism related issue.

\subsection{Size of Sample}

BhaktpurDurbarSquare of Bhaktpur District is the sample areas of this study. From the total tourism sector business/trade 25 samples and from the different tourist 50 sample people were selected by sample random sampling methods. These collected data had analysed by the used of descriptive statistics tools helps from the micro-excel program.

\section{Empirical Result and Discussion}

The analysis of data and discussion on the outcomes are made under different sub-headings.

\subsection{Distribution of Respondents by purpose of visit.}

Different tourist has different purpose for the visit of their destination. Tourist had visited the BhaktpurDurbar Square in for different purpose, which is shown by the help of the following table. 
Table: 4.1 Distributions of Respondents by purpose of visit

\begin{tabular}{|l|l|l|l|}
\hline S.N. & Religion & Frequency & Percentage \\
\hline 1 & Cultural & 8 & 16 \\
\hline 2 & Heritage & 11 & 22 \\
\hline 3 & Social & 23 & 46 \\
\hline 4 & Others & 8 & 16 \\
\hline 5 & Total & 50 & 100 \\
\hline
\end{tabular}

Source: Field Survey, 2019

The table 4.1 shows that the most attractive things that the tourist found in the BDS for Social sites which is $46 \%$, Heritage sites $22 \%$ Cultural and Social sites are $16 \%$ from the total respondents.

\subsection{Problem of Tourism Development}

There are different problems for tourism Development in BDS areas. Some main problems for the tourism development in that area explore by the helps of following table according to the respondent information of field survey.

\section{Table: 4.2. Problem of Tourism Development}

\begin{tabular}{|l|l|l|l|}
\hline S.N & Problem & Frequency & Percentage \\
\hline 1 & Transportation & 12 & 48 \\
\hline 2 & Drinking water & 9 & 36 \\
\hline 3 & Electricity & 2 & 8 \\
\hline 4 & Hotels and Sanitation & 2 & 8 \\
\hline 5 & If any another & 0 & 0 \\
\hline 7 & Total & 25 & 100 \\
\hline
\end{tabular}

Source: Field Survey, 2019

The table 4.2 show that as per the interview about the problem of tourism development.From the total respondents $48 \%$ felling transportation facilities problem,36\% felling Drinking Water problem, 8\% felling Electricity and Hotel as well as Sanitations problem.

\subsection{Motivation of Tourist for Re Visiting}

The various respondents have different option about the motivation of tourist re visiting Bhaktapur Durbar Square. This situation has been illustrating by the help of following table 


\section{Table: 4.3 Motivation of Tourist for Re Visiting}

Source: SSource: Field Survey, 2019

The table 4.3 shows that the information provided the respondent through the interview about the Motivation factor of tourist revisiting in BDS. From the total respondent32\% felling that the Keeping environment clean, 30\% filling that the Controlling unnecessary behaviour,18\% filling that the Maintaining Social Security for tourist, 12\% filling that the Keeping environment pleasant and peace, and8\% filling that the others factors.

\begin{tabular}{|l|l|l|l|}
\hline S.N & Prospect & Frequency & Percentage \\
\hline 1 & Keeping environment clean & 15 & 32 \\
\hline 2 & Controlling unnecessary Behavior & 16 & 30 \\
\hline 3 & Maintaining social security for tourist & 9 & 18 \\
\hline 4 & Keeping environment pleasant and peace & 6 & 12 \\
\hline 5 & Others & 4 & 8 \\
\hline 7 & Total & 50 & 100 \\
\hline
\end{tabular}

\subsection{Present Situation of Tourism.}

During the research, it was found that local people got normal, good and bad situation of tourism. Present situation of tourism in BDS had shown by the help of following table.

Table:4.4 Present Situation of Tourism.

\begin{tabular}{|l|l|l|l|}
\hline S.N & Situation & Frequency & Percentage \\
\hline 1 & Normal & 12 & 48 \\
\hline 2 & Good & 9 & 36 \\
\hline 3 & Bad & 4 & 16 \\
\hline 4 & Don`t know & 0 & 0 \\
\hline 5 & Total & 25 & 100 \\
\hline
\end{tabular}

Source: Field Survey, 2019

Table 4.4 shows that from the view of respondent about of present situation of tourism. From the total respondents48\% were felling that the normal situation, 36\%were felling that the good situation,16\%were felling that thebad situation and o \%felling that they had not known about the present situation of tourism.

\subsection{Impact of Tourism for Local People}

According to local people tourism has played an important role in the economic upgrading for people. They get opportunities to sell their goods and services locally to the hotels, restaurants and shops at reasonable price. Particularly those people who are engaged in handicraft and tourist oriented goods get good market locally with the tourism development. Main impact from the tourism in local community shows from the following table. 
Table: 4.5 Impact of Tourism for Local People

\begin{tabular}{|l|l|l|l|}
\hline S.N. & Impact & Frequency & Percentage \\
\hline 1 & Positive impact & 19 & 76 \\
\hline 2 & Negative impact & 4 & 16 \\
\hline 3 & No impact & 2 & 8 \\
\hline 4 & Total & 25 & 100 \\
\hline
\end{tabular}

Source: Field Survey, 2019

Table 4.5 clearly shows that the view of local people about impact of tourism were $76 \%$ respondent think that tourism bring positive impact in their livelihood,16\% respondent think thattourism bring negative impact in their livelihood and 8\%respondent think that without impact from tourism in their livelihood.

\subsection{Benefit from Tourism}

In the study area, local people get lots of benefits from the tourism. They feel change in their lifestyle. Different benefits had gained the local people from tourism explore by the following table.

\section{Table 4.6 Benefit from Tourism}

\begin{tabular}{|l|l|l|l|}
\hline S.N. & Benefits & Frequency & Percentage \\
\hline 1 & Income increase & 18 & 72 \\
\hline 2 & Job opportunity & 4 & 16 \\
\hline 3 & More education & 1 & 4 \\
\hline 4 & Awareness & 2 & 8 \\
\hline 5 & Others & 0 & 0 \\
\hline & Total & 25 & 100 \\
\hline
\end{tabular}

Source: Field Survey, 2019

Table no 4.6 shows that local people got different benefits from tourism. From the total respondent $72 \%$ benefited due to income increase, $16 \%$ benefited due to job opportunity, $4 \%$ benefited get more education by the help of tourists and 8 benefited of awareness.

\subsection{Importance of Tourism}

Most of the local people who were selected for sample of survey replied that tourism should have to be developed. Tourism industries are favourable and good for earning incomes and job opportunities for the local people. Some of them had bad impact for it. They said, "It is not important to development of tourism. It has brought negative impact on our culture, societies and phenomena." A few of them had very poor knowledge about it. They said,” We don't know it.” It is showed from table below. 
Table 4.7 Importance of Tourism

\begin{tabular}{|l|l|l|l|}
\hline S.N. & Importance & Frequency & percept \\
\hline 1 & It should have to developed & 20 & 80 \\
\hline 2 & It is not important & 4 & 16 \\
\hline 3 & Don't know & 1 & 4 \\
\hline & Total & 25 & 100 \\
\hline
\end{tabular}

Source: Field Survey, 2019

Table 4.7 shows that the view of respondents about important of tourism in sample area. From the total respondents $80 \%$ felling that the tourism should have to developed, $16 \%$ felling that the tourism was not important and $4 \%$ had not any idea.

\subsection{Purpose of Visit in Bhaktpur}

Purpose of visitNepal and Bhaktapur is diversity, historical and cultural monuments. The large number of tourists visits here for holiday pleasure, business, official work andothers. The purpose of visit tourist in Bhaktpur has been shown as the following table.

Table 4.8 Purpose of Visit in Bhaktapur

\begin{tabular}{|l|l|l|l|}
\hline S.N & Purpose & Frequency & Percentage \\
\hline 1 & For holiday pleasure & 20 & 40 \\
\hline 2 & For observe the new place & 10 & 20 \\
\hline 3 & For business activities & 5 & 10 \\
\hline 4 & For research (from college) & 10 & 20 \\
\hline 5 & Others & 5 & 10 \\
\hline 6 & Total & 50 & 100 \\
\hline
\end{tabular}

Source: Field Survey, 2019

Table 4.8 has shown that the purpose of visit in BDS. From the total respondentof tourists $40 \%$ come to visit here for holiday pleasure, $20 \%$ come for observe the new place, $10 \%$ come for business activities, $20 \%$ come for research(from college) and $10 \%$ come for other purpose.

\subsection{Attractive Things for Tourists in Bhaktapur}

Field survey questioner interview for tourist had maintained attractive things in Bhaktpru for the visit.Most of tourists were attracted by Culture and religious things. Some were attracted by historical things, beautiful ponds and neat and clean environment of Bhaktapur. Which were shown by the help of the below table: 
Table: 4.9 Attractive Things for Tourists in Bhaktapur

\begin{tabular}{|l|l|l|l|}
\hline S.N. & Attractive things & Frequency & Percentage \\
\hline 1 & Historical events & 19 & 38 \\
\hline 2 & Cultural and religious things & 27 & 54 \\
\hline 3 & Neat and clean environment & 3 & 6 \\
\hline 4 & Beautiful ponds & 1 & 2 \\
\hline & Total & 50 & 100 \\
\hline
\end{tabular}

Source: Field Survey 2019

Table 4.9 showed that the views of respondents about attractive things for tourist inBhaktpur.From the total respondent 54\% felling cultural and religious things,38\% felling historical events, $6 \%$ felling environment, $2 \%$ felling Ponds are attractive things for tourists in Bhaktpur.

\subsection{Length of Tourists Stay in Bhaktapur}

The length of tourist staying is crucial factor in tourism development. In order to develop tourism industry, it is not only necessary to increase no of tourist in flow but also increase their length of staying. Duration of staying by tourist in Bhaktapurexplore by the help of following table.

\section{Table: 4.10 Length of Tourist Stay in Bhaktapur}

\begin{tabular}{|l|l|l|l|}
\hline S.N. & Length & Frequency & Percentage \\
\hline 1 & 1 day & 5 & 33.33 \\
\hline 2 & $2-5$ days & 9 & 60 \\
\hline 3 & $5-10$ days & 1 & 6.66 \\
\hline & Total & 15 & 100 \\
\hline
\end{tabular}

Source: Field Survey 2019

Table 4.10 shows that from the total respondent 33.33\%felling tourists stay 1 day, $60 \%$ felling tourists stay for 2-5 days and 6.66\%felling tourists stay for 5-10 days. Length tourist stay is depends upon the purpose of tourists visiting in Bhaktpur.

\section{Conclusion}

This research analysis the problems and prospects of tourism development in Nepal with reference to BDS. Bhaktpur is a typical Newari culture and heritage city of Nepal which has leading capacity of tourism development in Nepal. Tourism is a main sector of Nepalese economic activities but there are so many problems in this sector. This research tries to analyse the problems as well as prefects of tourism development in Nepal. Present time both 
internal and foreign tourists are visiting in different place of Nepal. Maximum tourist has wanted to visit in Nepal due to our social diversity, old heritage and culture, clean environment and helpful behaviour of Nepalese people. They visit for holiday pleasure, observe the new place and business as well as gain new knowledge. Present situation of tourism sector is normal and good condition and tourism sector had positive impact in local community. It increase self- employment and employment opportunity which help to increase income and livingstandard of the local live hood Nepal improve and developed the tourism sector because there are many problems in tourism sector. To the developed the tourism sector it is necessary to encourage the tourist revisit Nepal. To solve the transportation facilities, increase physical facility in tourist area and increase the length to tourist stay time in Nepal.

\section{References}

Burger, V. (1978), the Economic Impact of Tourism in Nepal, an Input-Output Analysis. (Unpublished doctorialdissertation) University of Cornel, Hungary.

Butler, R.W. (1980), the concept of tourist area of cycle of evolution: implications of Managementof Resources. Canada Geographic 1 (15) 5-12.

CBS, (2011), Nepal in Figure, Central Bureau of Statistics, Kathmandu, Nepal

Dhakal, R.N. (2015), Overview of Tourism Development prospects in Nepal, Laura University of Applied Science, Kerala.

Prasain, A.B (2016), Contribution of tourism revenue in National Economy of Nepal. (Unpublished doctorial dissertation) Universityof Singhaniya, Rajasthan, India.

Satyal YRC (1988:7), Tourism in Nepal- a profile, Nath Publishing House Banaras

Shrestha, P. (2014), Tourism in Nepal, A Historical Perspectives and present trend of Development, Himalaya Journal of Sociology and Anthropology,6(2),120-135,Kathmandu, Nepal.

Sharma, O. (2003), Effects of Tourism on Economic Development of Nepal. The Economic Journal of Nepal, 26 (3), 114-127, Kathmandu.

Upadhyaya R.P. (2003), a Study of Tourism of Heading Sector for Economic Development of Nepal.(Unpublished doctorial dissertation)University of Lucknow, India.

World Tourism Organization, (1996), Framework for the collection publication of tourism Statistics: Kathmandu, WTO

World Travel \& Tourism Council, (2018), Travel \& Tourism Economic impact 2018, Nepal: Author. 